\title{
Creating Conditions for Successful Development of Innovation Projects
}

\author{
Alla Nikonorova \\ Department of Management and Marketing \\ Moscow Witte University \\ Moscow, Russia \\ E-mail: nikonorova-av@mail.ru
}

\author{
Dmitry Morkovkin \\ Department of Economic theory \\ Financial University under Government of the Russian \\ Federation \\ Russian State University for the Humanities \\ Moscow, Russia \\ E-mail: MorkovkinDE@mail.ru
}

\author{
Valery Nezamaikin \\ Russian State University for the Humanities \\ Moscow, Russia \\ E-mail: NezamaikinVN@mail.ru
}

\begin{abstract}
The article reveals the questions of creating conditions for successful development of innovative projects in the Russian Federation. Current changes of technologies, digitalization of the most processes and other factors make the realization of unique ideas possible. Creation of innovative ecosystems aids innovators in elaboration and usage of keydrivers of their projects. The tendency in usage of information and communication technologies is analyzed and illustrated with the statistical data. The model for analyzing the process of the simultaneous influence of innovative ecosystem, the external factors, and internal key-drivers of the project is submitted in the article. Its implementation can facilitate the decision making process for managers engaged in development of innovation projects.
\end{abstract}

Keywords-innovative development; decision making; keydrivers of development; innovation projects; innovative infrastructure; innovative ecosystem

\section{INTRODUCTION}

Creation of the conditions for realization of a successful innovation project is a complex task. One of the ways of its solving is development of an innovative ecosystem. The diverse resources of an innovative ecosystem aids in fostering new projects and prompt introduction of innovations as a result. Innovative ecosystems in the Russian Federation became the platform for communication of the State, business, and science. Development of innovative ecosystem implies systematic amelioration in many aspects. The process of introducing new knowledge in practice is always very risky. As a rule innovation which is derived from new knowledge is of very high costs, and its realization within conditions of existing innovative ecosystem proves to be chipper.
In conditions of innovative ecosystem the advanced ideas can be implemented much quicker, and this fact can be of principal importance for their developers. In conditions of digital economy the capacity of companies for cooperation, alliances, entering external partnership is increasing.

The digitalization of economy can be the means of improving the quality of life and increasing the efficiency of projects. The growth in the share of innovative products is contributing to the gross domestic product. Many companies are trying to strengthen their positions with implementing the strategy of forming consortiums for producing new competitive products. The creation of innovative regional clusters of small and medium-sized businesses focused on the development and implementation of innovative activities can be the basis of the mechanism of diversification of the national economy [1].

The level of the economic development of the country is determined by speed, volume, and depth of the innovation process. The innovation ecosystem creates conditions for successful creation and development of enterprises. It possesses the feature of self-regulation and self-organization [2].

Despite of the fact that numerous works in the field of innovation project management are created, the elaboration of new tools and techniques is still required.

Development of the conditions which are important for realization of successful innovation projects should be planned on the basis of the analysis of external and internal factors.

The thorough analysis of the specifics of innovative ecosystem, the external factors, and internal key-drivers of the project is to be fulfilled. 
The model described in this article aims to facilitate the elaboration of key-drivers of a project and the process of decision-making for managers engaged in realization of innovation projects.

\section{MODERN CONDITIONS OF INNOVATIVE PROJECTS DEVELOPMENT}

At present almost all spheres of social and economic activities are involved in digital modernization. New technologies are implemented in industry and science, business and government, society and education. The scale of changes is reaching a new level and affects the ecosystems of whole cities and countries, changing the fundamental approaches to the transfer of experience. Artificial intelligence technologies are becoming available for small and medium businesses thanks to cloud services and open libraries actively penetrating everyday activity. Voice assistants, unmanned vehicles, robots in call centers have already became a part of everyday life. Implementation of new technologies helps in surmounting the lack of financial or intellectual resources, solving diverse tasks.

Implementation of big data, overall robotization and the internet of things, artificial intelligence have already led to the increase in industrial labor efficiency, but a further breakthrough is still possible. It can be made on the basis of creation of appropriate infrastructure. Disruptive innovations are appearing and spreading at an ever increasing rate, they bring even greater changes which will affect companies, state organizations, and private citizens.
Innovative projects are interdependent and linked to resources, dates, performers, methodology and technology. Innovative ecosystem creates the necessary environment for initiation and implementation of innovative projects. Rapid dissemination of knowledge and competencies, their transformation into new products and services become prerequisites for further technological growth. Many companies that work on implementing the digital transformation objective are forced to change from the product-centered to the client-centered business management model. More and more businesses are moving from a model of selling goods to a model of selling services. Modern companies are using the network-like management and horizontal relationship practices. The usage of digital technology is making it possible to conduct managerial activity and work with consumers in real time, while the implementation of information technology is opening up vast vistas for business development and helping boost the efficiency of the activities [3].

Development and commercialization of new technologies, the popularization of world technology brands and the creation of new tools for international cooperation in the field of innovation increase both opportunities and risks for new innovative projects.

The data of statistics vindicate that information and communication technologies are becoming more and more popular. The trends in dynamics of changes in quantity of organizations that use IT technologies are shown in the "Table I" [4].

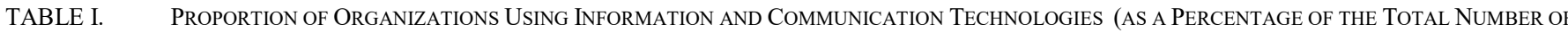
ORGANIZATIONS SURVEYED)

\begin{tabular}{|l|l|l|l|l|l|l|l|}
\hline \multicolumn{1}{|c|}{ Organizations that use: } & \multicolumn{1}{|c|}{$\mathbf{2 0 0 3}$} & $\mathbf{2 0 0 6}$ & \multicolumn{1}{|c|}{$\mathbf{2 0 0 9}$} & $\mathbf{2 0 1 2}$ & $\mathbf{2 0 1 5}$ & $\mathbf{2 0 1 6}$ & $\mathbf{2 0 1 7}$ \\
\hline personal computers & 84,6 & 99,3 & 93,7 & 94,0 & 92,3 & 92,4 & 92,1 \\
servers & 8,3 & 11,3 & 16 & 18,9 & 47,7 & 50,8 & 50,6 \\
email & 48,6 & 63,6 & 78,5 & 85,2 & 84,0 & 87,6 & 88,3 \\
global information network & 50,1 & 62,5 & 79,3 & 87,5 & 89,0 & 89,6 & 89,7 \\
Organizations that have web sites & 13,5 & 21,1 & 24,1 & 37,8 & 42,6 & 45,9 & 47,4 \\
\hline
\end{tabular}

As it can be seen the steady tendency to rise is observed in the proportion of organizations using information and communication technologies.

In these conditions of environment of large-scale digitalization, creation of the model for analyzing the process of the external and internal factors influence on the innovation project can be expedient.

\section{CREATION OF THE MODEL FOR DEVELOPMENT OF KEY-DRIVERS FOR AN INNOVATION PROJECT}

The world practice shows that innovative ecosystems have another positive characteristic. That is the fact that the numerous innovative projects have an opportunity to use facilities and advantages of innovative ecosystems. That causes reduction of expenses for implementation of each project, facilitates the creation of well-established mechanisms for continuous commercialization of developments. However, this approach demands detailed studying, first of all, from the point of view of adaptation of the international experience to the Russian conditions [5].

Innovative ecosystem can provide substantial support for new projects. The benevolent infrastructure, innovative centers and technoparks make favorable conditions for successful development.

The monitoring of external and internal factors helps to overcome the difficulties and increase sustainability of the project.

Innovation project significantly depends on the situation with demand and supply on the market. The market situation is of great importance, as it is connected directly with the commercialization of the new idea.

The society also renders serious influence on the development of an innovative project, this influence can be:

- Social;

- psychological; 
- Economic.

Among external factors should be distinguished such factors as:

- Conditions of infractructure;

- Availability of specialized innovative centers and technoparks;

- The system of communication;

- The latest achievements of science.

The analysis of conditions for development of an innovation project permits managers to distinguish and elaborate its key-drivers. In order to improve the efficiency of management it is possible to distinguish the following key-drivers of an innovative project:
- Blockchain technologies;

- Technologies of production;

- Additional services;

- Time-management methods;

- Education,

- R@d and experience.

The fostering of key-drivers of the innovative project helps to deploy its potential.

The submitted model for analyzing the process of influence on the innovation project of innovative ecosystem, external factors, and internal key-drivers is represented on the "Fig. 1".

- Digitalization;

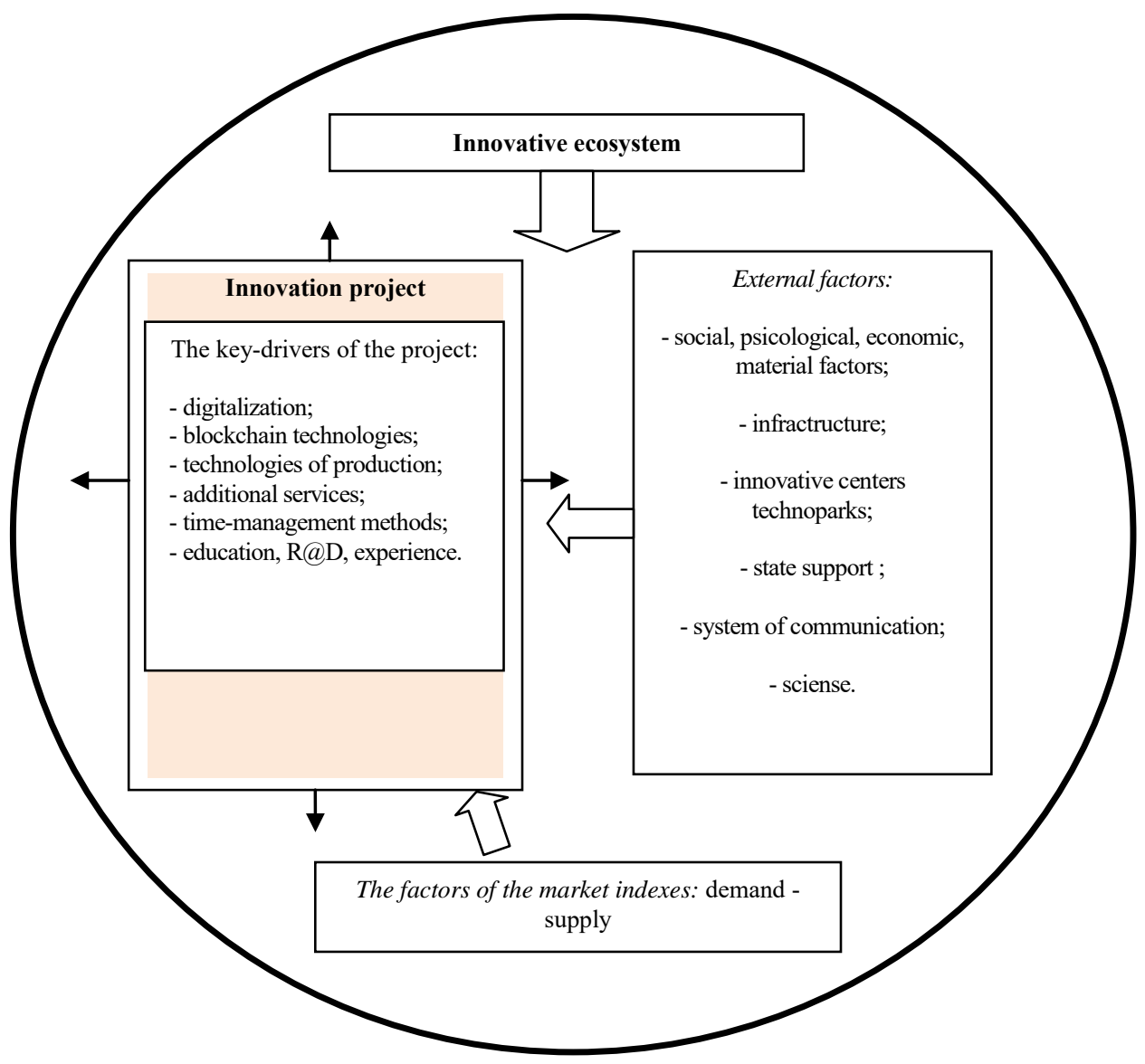

Fig. 1. The model for analyzing the process of influence on the innovation project of innovative ecosystem, external factors, and internal key-drivers.

Despite the huge opportunities that new technological realities are opening up, they also bring with them a number of risks. The necessary changes may be too much for companies and projects. Governments may have difficulties in regulation and introduction of new technologies, and a range of new economic and social imbalances may develop [6].
The analysis of the process of influence on the innovation project of innovative ecosystem permits to determine the factors that hamper the implementation of novelties and to identify the key-drivers of an innovative project for their future development

Significant upfront costs, long payback periods, specific needs of customers, psychological barriers in the processes of initiating and implementing of innovative projects 
increase the risks of failure. In these conditions the successful development of innovation projects can be more sustainable in case they are realized within an innovative ecosystem, which creates favorable conditions for constant transfer of requests from the market to the scientific environment and back.

\section{CONCLUSION}

Successful development of innovative projects significantly depends on conditions in which they exist. Even outstanding and eminent new ideas are not guaranteed to become prosperous. Creation of innovative ecosystems aids in fostering prospective projects.

Modern technologies and methods make possible development of products and services that had never existed before. Digitalization and introduction of new technologies affect nowadays all industries, including even the most conservative of them. Technological growth can be provoked with the rapid dissemination of knowledge and competencies, their transformation into new products and services.

The quantity of organizations that use information and communication technologies constantly increases. This fact is conformed not only with common observations and experience but also with the data of statistics.

Innovative projects seriously depend on demand and supply indexes of the market, as it is directly related with the commercialization of the new idea. Implementation of new technologies and approaches allow even small projects to compete effectively on the market.

In conditions of the Russian Federation the innovative ecosystems are often supported by the State, and as a result the conditions for realization of new projects are more favorable in them in comparison with other regions.

Innovative ecosystems can provide innovative projects with benevolent infrastructure, conditions for scientific researches, getting special or additional knowledge, business communications. Conditions of innovative ecosystems enable businesses to boost sales, establish new partnerships, and introduce culture of entrepreneurship via implementing innovative technologies.

All these opportunities aid innovators in elaborations the key-drivers of their projects and deploy its potential taking into account the need of market economy in continuous upgrading of goods, services, and technologies.

Successful development of innovative projects depends on many external and internal factors. To overcome the difficulties innovators require in elaboration and usage of key-drivers for their projects.

In the modern conditions it is possible to specially distinguish such key-drivers of successful innovative projects as:

- Digitalization;

- Blockchain technologies;

- Technologies of production;
- Additional services;

- Time-management methods;

- Education, r@d, and experience.

They are formed under the influence of external factors such as social, psicological, economic, material factors, conditions of infrastructure, availability of specialized innovative centers and technoparks, the system of communication, the latest achievements of science.

Current digitalization of the most processes, which can be considered as a distinctive phenomenon of the modern time, can facilitate and expedite the implementation of new ideas. The elaboration of the model for analyzing the process of the simultaneous influence of innovative ecosystem, external factors, and internal key-drivers of the project is expedient. Development and implementation of such model for analyzing the process of the simultaneous influence of external and internal factors can aid in facilitation the decision-making process and elaboration of key-drivers for innovative projects.

\section{REFERENCES}

[1] M. Izmailova, E. Antusak, M. Veselovsky, et al. Small and medium innovation business as a mechanism to diversify the Russian economy // 10th International Days of Statistics and Economics. 2016 pp.691-700

[2] P.A. Suhanova Innovative infrastructure in the regional innovation ecosystem and its elements // Bulletin of the Siberian Institute of business and information technology. 2012. № 3 (3). pp. 49-52.

[3] M.Y. Veselovsky, A.V. Nikonorova, A.A. Stepanov, N.L Krasyukova, I.V. Bitkina. The development of innovative startups in Russia: the regional aspect // Academy of Strategic Management Journal. 2017. Vol. 16. № 1. pp. 197-208.

[4] Federal State Statistics Service of the Russian Federation (2017) Science and Innovations. Retrieved October 19, 2018, from http://www.gks.ru/wps/wcm/connect/rosstat_main/rosstat/ru/statistics /science_and_innovations/it_technology/\#

[5] N.V. Kiseleva, M.V. Panichkina, E.N. Klochko, A.V. Nikonorova S.V. Kireev Creation of clusters of small enterprises of the region // International Journal of Economics and Financial Issues. 2016. Vol.6. № S2. pp. 294-297.

[6] A. Nikonorova, D. Morkovkin, N. Isaichikova, V. Nezamaikin. Improvement of innovative infrastructure as a means of economic development // 3rd International Confeence on Economics, Management, Law and Education (EMLE 2017): Advances in Economics, Business and Management Research, Vol.3 - P. 1-4. 